\title{
Study on Railway Container Station Efficiency Analysis
}

\author{
Shouwen $\mathrm{Ji}^{1, \mathrm{a}}$, Huiting Wang ${ }^{2, \mathrm{~b}}$ and Yanbin Yao ${ }^{3, \mathrm{c}}$ \\ ${ }^{1}$ School of Traffic and Transportation, Beijing Jiaotong University, Beijing, China \\ ${ }^{2}$ School of Traffic and Transportation, Beijing Jiaotong University, Beijing, China \\ ${ }^{3}$ Beijing Capital International Airport Co., Ltd. , Beijing, China \\ aemail: 13910780769@126.com, bemail: 5210576615@163.com, cemail: \\ yaoyanbin1982@sina.com
}

\begin{abstract}
Keywords: Container Station; Operation Efficiency; Gray Correlation; Allocation of Resources
\end{abstract}
\begin{abstract}
As rapid development of economy and IT in China, logistics facing new environment, railway container freight station is bound to the large-scale, centralized, large-scale, modern direction. However, development of container transport is restricted due to excessive freight station, limited investment and container resources under competence and inefficient operation. In this paper, it makes a more comprehensive and systematic study of the influence factors for the railway container station efficiency using the grey correlation analysis method to improve operational efficiency for stations and provide the reference for the railway container station layout.
\end{abstract}

\section{Introduction}

As rapid development of economy and IT in China, logistics facing new environment, railway container freight station is bound to the large-scale, centralized, large-scale, modern direction to meet this demand. Enterprises of container business is looking forward to growing up to compress processing station, adjust container freight station layout reasonably, set the container center stations and handling stations for nodes, open the point to point container line as the main form of transport organization and improve the efficiency continuously. Impact analysis of operational efficiency for container station can optimize the allocation of limited resources, improve operational efficiency for stations and provide the reference for the railway container station layout. In this paper, it makes a more comprehensive and systematic study of the influence factors for the railway container station efficiency using the grey correlation analysis method on the basis of widely accessible and in-depth study of international development status[1].

Container freight stations are divided into container center stations, container handling stations and general container stations by their roles in the network[2]. In order to change the excessive number, unreasonable distribution, poor level of the technical equipment and the low utilization rate of resources of container stations, it needs to intensify building the center stations and container handling stations, close some stations with small volume and low operation efficiency and keep the limited capacity resource focusing on the reserved container stations. The container station this paper has analyzed means the general container station.

\section{Model Construction}

For railway container station's working efficiency, the annual container volume and annual container tonnage (i.e. the amount of work) can manifest most the container stations' output level in the industry. It is also an important measure for the relative size, investment scale and management level of the container stations. So this model also sets them as indicators for the evaluation of operating efficiency of container stations. Then this model sets the number of station loading lines, the effective length of station loading lines, yard area and the capacity of handling equipment as the influence factors for the railway container station efficiency[4][5].

The model in this paper analyzes the relationship between the container station operation index and the influencing factors using the grey correlation analysis method. Then this paper sorts the 
influencing factors and calculates the relative operating efficiency. Calculation steps using the grey correlation analysis method are as follows[3].

The first step: determining the analysis sequence.

Fist, the paper determines the reference sequence and comparative sequence according to each influencing factor. Data sequence known as the reference sequence can reflect the features of the system behavior. Also it is called the mother sequence. Data series of factors that can affect the behavior of the system is known as the comparative sequence. Also it is called the sub sequence.

The reference sequence: $Y=\{Y(k) \mid k=1,2, \cdots, n\}$

The comparative sequence: $X_{i}=\left\{X_{i}(k) \mid k=1,2, \cdots, n\right\}, i=1,2, \cdots m$

The second step: Making variables with no units of measurement.

Due to the different factors' sequences with different data units, it is difficult to obtain the correct comparing conclusion. So the grey correlation analysis method needs to make variables with no units of measurement first. In this paper, it uses the average method to remove the units of the data. The average method is making each sample data divided by the average of this data sample. Formula is as follows.

$$
x_{i}(k)=\frac{X_{i}(k)}{X_{i}(l)}, k=1,2, \Lambda, n ; i=0,1,2, \Lambda, m
$$

$X_{i}(l)$ is the average of this data sample.

The third step: Calculating the correlation coefficient $Y(K)$ and $X_{I}(K)$.

$$
\begin{aligned}
& \xi_{i}(k)=\frac{\min _{i} \min _{k}\left|y(k)-x_{i}(k)\right|+\rho \max _{i} \max _{k}\left|y(k)-x_{i}(k)\right|}{\left|y(k)-x_{i}(k)\right|+\rho \max _{i} \max _{k}\left|y(k)-x_{i}(k)\right|} \\
& \Delta_{i}(k)=\left|y(k)-x_{i}(k)\right| \\
& \xi_{i}(k)=\frac{\min _{i} \min _{k} \Delta_{i}(k)+\rho \max _{i} \max _{k} \Delta_{i}(k)}{\Delta_{i}(k)+\rho \max \max _{i} \Delta_{i}(k)} \\
& \rho \in(0, \infty)
\end{aligned}
$$

$\rho$ is the resolution factor. The smaller the $\rho$ is, the greater the resolution is. The range of $\rho$ is $(0,1)$. To specific value of $\rho$ can be according to actual situation. If $\rho \leq 0.5463$, it gets the best resolution. This paper sets $\rho=0.5$.

The fourth step: Calculating correlation value.

The correlation coefficient is the connection degree of each moment between the reference sequence and comparative sequence. They are a series of values, and it is not easy to compare the related degree. This model makes all the correlation coefficient into a value. It is called correlation value. The formula of correlation value $r_{i}$ is as follows.

$$
r_{i}=\frac{1}{n} \sum_{k=1}^{n} \xi_{i}(k), k=1,2, \Lambda, n
$$

The fifth step: Ranking the correlation value.

This model ranks the correlation values. The correlation value is greater, the reference sequence and comparative sequence are more similar. Thus the influencing of the influence factor is greater.

\section{The calculation of the empirical model}

The data in this paper is from 46 container handling stations in the Beijing Railway Bureau. This paper selects 12 items of them as the research objects. They are Dahongmen, Handan, Hengshui, Zhangjiajienan, Xiyingmen, Cangzhou, Shinan, Xingtai, Shahe, Shacheng, Chengde and Langfang. This paper collects the data of the number of station loading lines, the effective length of station loading lines, yard area, the capacity of handling equipment and the annual container tonnage of every railway container station of 2012.

This paper makes variables with no units of measurement first. It makes the average value for 
each column. the average value is $X_{i}(l)$. Then this paper makes the raw data into the formula.

$$
x_{i}(k)=\frac{X_{i}(k)}{X_{i}(l)}, k=1,2, \Lambda, n ; i=0,1,2, \Lambda, m
$$

Then it gets a unified data table. The data is shown in table1.

Table1 the unified data with on units of 2012

\begin{tabular}{|c|c|c|c|c|c|c|}
\hline 2012 & & & & & & $\begin{array}{c}\text { Amount of } \\
\text { Work }\end{array}$ \\
\hline No. & Station Name & $\begin{array}{c}\text { the Number } \\
\text { of Station } \\
\text { Loading } \\
\text { Lines }\end{array}$ & $\begin{array}{l}\text { the Effective } \\
\text { Length of } \\
\text { Station } \\
\text { Loading Lines }\end{array}$ & $\begin{array}{l}\text { Yard } \\
\text { Area }\end{array}$ & $\begin{array}{c}\text { the } \\
\text { Capacity of } \\
\text { Handling } \\
\text { Equipment }\end{array}$ & $\begin{array}{c}\text { Annual } \\
\text { Container } \\
\text { Tonnage }\end{array}$ \\
\hline 1 & Dahongmen & 1.8 & 1.938 & 4.196 & 1.286 & 2.040 \\
\hline 2 & Handan & 1.2 & 0.829 & 0.218 & 1.714 & 0.582 \\
\hline 3 & Hengshui & 1.2 & 1.948 & 1.955 & 1.714 & 0.274 \\
\hline 4 & Zhangjiajienan & 1.2 & 1.106 & 0.996 & 0.857 & 2.212 \\
\hline 5 & Xiyingmen & 0.6 & 0.803 & 0.768 & 1.286 & 0.603 \\
\hline 6 & Cangzhou & 0.6 & 1.121 & 0.140 & 0.429 & 1.078 \\
\hline 7 & Shinan & 0.6 & 0.518 & 0.893 & 0.857 & 3.343 \\
\hline 8 & Xingtai & 1.2 & 1.046 & 0.718 & 1.286 & 0.241 \\
\hline 9 & Shahe & 1.2 & 0.412 & 0.614 & 0.429 & 1.090 \\
\hline 10 & Shacheng & 0.6 & 0.359 & 0.456 & 0.429 & 0.097 \\
\hline 11 & Chengde & 0.6 & 0.889 & 0.348 & 0.429 & 0.070 \\
\hline 12 & Langfang & 1.2 & 1.0298 & 0.697 & 1.286 & 0.369 \\
\hline
\end{tabular}

Then this paper calculates the correlation coefficient. The unified data with on units is made into the formula.

$$
\xi_{i}(k)=\frac{\min _{i} \min _{k}\left|y(k)-x_{i}(k)\right|+\rho \max _{i} \max _{k}\left|y(k)-x_{i}(k)\right|}{\left|y(k)-x_{i}(k)\right|+\rho \max _{i} \max _{k}\left|y(k)-x_{i}(k)\right|}
$$

$\left|y(k)-x_{i}(k)\right|$ is the comparison value of the influencing factors and the annual container tonnage. The data is shown in table2.

Table2 the correlation coefficient of the sample of 2012

\begin{tabular}{|c|c|c|c|c|c|}
\hline 2012 & \multicolumn{5}{|c|}{ the Correlation Coefficient } \\
\hline No. & Station Name & $\begin{array}{c}\text { the Number of } \\
\text { Station Loading } \\
\text { Lines }\end{array}$ & $\begin{array}{c}\text { the Effective } \\
\text { Length of Station } \\
\text { Loading Lines }\end{array}$ & Yard Area & $\begin{array}{c}\text { the Capacity of } \\
\text { Handling } \\
\text { Equipment }\end{array}$ \\
\hline 1 & Dahongmen & 0.857 & 0.935 & 0.397 & 0.653 \\
\hline 2 & Handan & 0.697 & 0.853 & 0.797 & 0.556 \\
\hline 3 & Hengshui & 0.605 & 0.459 & 0.458 & 0.496 \\
\hline 4 & Zhangjiajienan & 0.584 & 0.562 & 0.539 & 0.511 \\
\hline 5 & Xiyingmen & 1 & 0.878 & 0.898 & 0.676 \\
\hline 6 & Cangzhou & 0.749 & 0.973 & 0.602 & 0.687 \\
\hline 7 & Shinan & 0.341 & 0.334 & 0.367 & 0.363 \\
\hline 8 & Xingtai & 0.597 & 0.638 & 0.749 & 0.576 \\
\hline 9 & Shahe & 0.930 & 0.677 & 0.750 & 0.683 \\
\hline 10 & Shacheng & 0.739 & 0.845 & 0.799 & 0.812 \\
\hline 11 & Chengde & 0.729 & 0.634 & 0.838 & 0.780 \\
\hline 12 & Langfang & 0.631 & 0.683 & 0.813 & 0.608 \\
\hline
\end{tabular}

Then this paper calculates correlation value. It calculates the average of each column, and ranks 
the results. At last weights are calculated. The data is shown in table3.

Table3 the results of the correlation value of the sample

\begin{tabular}{|c|c|c|c|c|}
\hline 2012 & $\begin{array}{c}\text { the Number of } \\
\text { Station Loading } \\
\text { Lines }\end{array}$ & $\begin{array}{c}\text { the Effective } \\
\text { Length of Station } \\
\text { Loading Lines }\end{array}$ & $\begin{array}{c}\text { Yard } \\
\text { Area }\end{array}$ & $\begin{array}{c}\text { the Capacity of } \\
\text { Handling } \\
\text { Equipment }\end{array}$ \\
\hline $\begin{array}{c}\text { The Average of the } \\
\text { Correlation Value }\end{array}$ & 0.705 & 0.706 & 0.667 & 0.618 \\
\hline $\begin{array}{c}\text { The Ranking of the } \\
\text { Correlation value }\end{array}$ & 2 & 1 & 3 & 4 \\
\hline The weights & 0.261 & 0.262 & 0.247 & 0.229 \\
\hline
\end{tabular}

Then this paper calculates the relative resource numerical of each railway container station. It is called the relative operation efficiency. The relative operation efficiency is not the actual operation efficiency.

The relative operation efficiency=Annual container tonnage/( Influencing factors*The weight of every influencing factor)

The data of the relative operation efficiency is shown in table 4.

Table 4 the relative operation efficiency of the sample of 2012

\begin{tabular}{|c|c|c|c|c|c|c|c|}
\hline 2012 & & & & & & $\begin{array}{c}\text { Amount of } \\
\text { Work }\end{array}$ & $\begin{array}{c}\text { the } \\
\text { Relative } \\
\text { Amount }\end{array}$ \\
\hline No. & Station Name & $\begin{array}{c}\text { Number } \\
\text { of Station } \\
\text { Loading } \\
\text { Lines }\end{array}$ & $\begin{array}{c}\text { the Effective } \\
\text { Length of } \\
\text { Station } \\
\text { Loading } \\
\text { Lines }\end{array}$ & $\begin{array}{c}\text { Yard } \\
\text { Area }\end{array}$ & $\begin{array}{c}\text { the } \\
\text { Capacity } \\
\text { of } \\
\text { Handling } \\
\text { Equipment }\end{array}$ & $\begin{array}{c}\text { Annual } \\
\text { Container } \\
\text { Tonnage } \\
\text { Relative } \\
\text { Operation } \\
\text { Efficiency }\end{array}$ & \\
\hline 1 & Dahongmen & 1.8 & 1.938 & 4.196 & 1.286 & 2.040 & 0.883 \\
\hline 2 & Handan & 1.2 & 0.829 & 0.218 & 1.714 & 0.582 & 0.595 \\
\hline 3 & Hengshui & 1.2 & 1.948 & 1.955 & 1.714 & 0.274 & 0.161 \\
\hline 4 & Zhangjiajienan & 1.2 & 1.106 & 0.996 & 0.857 & 2.212 & 2.115 \\
\hline 5 & Xiyingmen & 0.6 & 0.803 & 0.768 & 1.286 & 0.603 & 0.708 \\
\hline 6 & Cangzhou & 0.6 & 1.121 & 0.140 & 0.429 & 1.078 & 1.848 \\
\hline 7 & Shinan & 0.6 & 0.518 & 0.893 & 0.858 & 3.343 & 4.707 \\
\hline 8 & Xingtai & 1.2 & 1.046 & 0.718 & 1.286 & 0.241 & 0.228 \\
\hline 9 & Shahe & 1.2 & 0.412 & 0.614 & 0.429 & 1.090 & 1.622 \\
\hline 10 & Shacheng & 0.6 & 0.359 & 0.456 & 0.429 & 0.097 & 0.209 \\
\hline 11 & Chengde & 0.6 & 0.889 & 0.348 & 0.429 & 0.070 & 0.122 \\
\hline 12 & Langfang & 1.2 & 1.030 & 0.697 & 1.289 & 0.369 & 0.351 \\
\hline
\end{tabular}

The higher value of the relative operation efficiency means the greater of the operation management efficiency for the railway container station. It is shown that the Shinan station has the highest operation efficiency, and the Chengde station has the lowest operation efficiency.

\section{Conclusion}

This paper calculates the gray correlation coefficients of the four variable factors and the evaluation index. Then it gets the average value of the correlation coefficients. It is called the correlation value. The results can be found from the data that the number of station loading lines and the effective length of station loading lines have a higher level of correlation with the annual container tonnage. Influence of these two variables is relatively large. The yard area and the capacity of handling equipment are the secondary factors. Therefore, improving the number of station loading lines and the effective length of station loading lines is the chief operating efficiency 
solutions to develop the railway container station. When these two aspects have been enhanced or there are obstacles to improve them, we can expand yard area and increase the number of loading machineries to improve operating efficiency.

It can ben found from the data that Shinan station has the highest relative operation efficiency. The Influencing factors indexes of Shinan are in the medium level among the 12 railway container stations, while Shinan has the highest value of annual container tonnage. This can show its great operation efficiency. It should continue to maintain for the high efficiency container station, and it should append investment to seek the maximize benefits in accordance with the primary and secondary influence factors. For some stations which have advantages of hardware resource and relatively lower efficiency, we should pay more attention to the optimization of software. For example, we should improve the work flow or raise the level of the management.

\section{Acknowledgement}

In this paper, the research was sponsored by the Science and Technology Support Program Supply Chain Logistics Real-time Monitoring, Management and Control (Project No.2014BAH23F01).

\section{References}

[1] Shunhu Su. Research on Chinese Railway Container Transportation Development and Practice [M].Beijing: Chinese Railway Publishing House.2010.

[2] Huanying Yue. Research on Railway Logistics Centers and Specialized Station Railway Container Train Organization [D]. Beijing Jiaotong University.2009.

[3] Guangming Zeng, Chunping Yang, Beiwei Zeng. Research on Grey Relational Comprehensive Evaluation Method with Environmental Impact. Environmental Engineering Department of Hunan University.1995.

[4] Yaping Shi. Research on Efficiency Evaluation for Railway Container Station. China Railway Container Transport Co. Ltd. Guangzhou branch.2011.

[5]Hui Yang. Railway Container Transport System Development Countermeasures.Hunan: Hunan Railway Professional Technology Institute of Science and Technology.2008. 